\section{Exercício intermitente de alta intensidade como alternativa na reabilitacão cardiovascular: uma metanálise}

\author{
High intensity intermittent training \\ as an alternative in cardiovascular \\ rehabilitation: a meta-analysis
}

\author{
Victor Silveira Coswig \\ Leandro Quadro Corrêa ${ }^{2}$ \\ Antônio Evanhoé Pereira de Souza Sobrinho ${ }^{3}$ \\ Fabrício Boscolo Del Vecchio
}

\section{RESUMO}

O objetivo desta metanálise testar a hipótese de que exercícios intermitentes de alta intensidade (HIIT) apresentam efeito superior ao exercício contínuo de intensidade moderada (MICE) sobre o $\mathrm{VO}_{2 \text { pico }}, \mathrm{FC}_{\text {pico }}$, fração de ejeção do ventrículo esquerdo (LVEF) e dilatação arterial fluxo-mediada (FMD) em pacientes com infarto agudo do miocárdio (IAM), doença arterial coronariana (DAC) e insuficiência cardíaca (IC). As bases de dados eletrônicas PubMed, EBSCOhost e Science Direct foram acessadas, além de buscas nas referências dos próprios artigos. Incluíram-se 12 artigos com total de 239 pacientes que realizaram sessões de HIIT $(61,88 \pm 5,88$ anos) e de 276 que realizaram MICE $(62,43 \pm 4,85$ anos). Verificouse efeito favorável ao HIIT em comparação ao MICE no $\mathrm{VO}_{2 \text { pico }}(\mathrm{Z}=8,22 ; \mathrm{p}<0,0001)$ e $\operatorname{LVEF}(Z=3,25 ; \mathrm{p}=0,001)$, porém sem diferença na $\mathrm{FC}_{\text {pico }}(\mathrm{Z}=1,15 ; \mathrm{p}=0,24)$ e $\operatorname{FMD}(\mathrm{z}=0,12$; $\mathrm{p}=0,9)$. Pode-se concluir que o HIIT proporciona benefícios senão superiores, ao menos equivalentes em ganhos fisiológicos relacionados à morbidade e mortalidade de pessoas com problemas cardiovasculares.

\section{PALAVRAS-CHAVE}

Doenças Cardiovasculares; Exercício; Insuficiência cardíaca; Aptidão física

\begin{abstract}
The purpose of this meta-analysis was to review systematically the literature and quantify the effect size of interventions with continuous and intermittent exercise in patients with acute myocardial infarction (AMI), coronary beart disease (CHD) and heart failure (HF). The bypothesis tested was that high-intensity intermittent exercise (HIIT) offers superior effect related to continuous exercise of moderate intensity (MICE) on $\mathrm{VO}_{2 \text { max }}, \mathrm{HR}_{\text {peak }}$, left ventricular ejection fraction (LVEF) and flo$w$-mediated arterial dilation (FMD) in these patients. Electronic databases PubMed, EBSCObost and Science Direct were accessed, as well as searches in references of the articles themselves. Twelve articles were included in the analyses and, after searches and evaluations of retrieved studies, $75 \%$ had scored $\geq 7$ points in PEDro scale. Were extracted information of 239 patients who underwent sessions of HIIT $(61.88 \pm 5.89$ years $)$ and 276 who performed sessions of MICE $(62.43 \pm 4.85$ years). Dose response effect was found in favour of HIIT compared to MICE in $V_{2 \max }(Z=8.22$; $p<0.0001)$ and LVEF $(Z=3.25 ; p=0.001)$, however there was no difference in respect of $H R_{\text {peak }}$ $(Z=1.15 ; p=0.24)$ and FMD $(z=0.12 ; p=0.9)$. Thus, we conclude that HIIT provides higher, or at least equivalent, benefits in physiological gains related to morbidity and mortality in people with cardiovascular problems.
\end{abstract}

\section{KEYWORDS}

Cardiovascular Diseases; Exercise; Heart Failure; Physical Fitness.
Rev Bras Ativ Fís Saúde p. 340-351 DOI

http://dx.doi.org/10.12820/rbafs.v.20n4p340

1 Escola Superior de Educação Física, Universidade Federal de Pelotas, Pelotas, RS, Brasil

2 Universidade Federal do Rio Grande, Instituto de Educação, Educação Física, Rio Grande, RS, Brasil

3 Escola Superior de Educação Física, Universidade da Região da Campanha, Bagé, RS, Brasil 


\section{INTRODUÇÃO}

A atividade física integra a abordagem médica para prevenção das doenças cardiovasculares, que configuram a primeira causa de mortalidade no mundo entre 2000 e $2012^{1,2}$, e recomendações para a prática de atividade física envolvem exercícios com longa duração (20 a $40 \mathrm{~min}$ ), em intensidade moderada (40 a $80 \% \mathrm{VO}_{2 \max }$ ), com frequência mínima de três sessões semanais ${ }^{3-7}$. Entretanto, poucas pessoas dispõem/disponibilizam muito tempo para se exercitar, e o exercício intermitente de alta intensidade (HIIT) se constitui como alternativa viável para esta barreira ${ }^{8-10}$. O HIIT é exercício que intercala atividade de curta duração e intensidades elevadas com recuperação ativa ou passiva, sendo que as ações/esforços podem durar entre 5 minutos e seis segundos com intensidades acima do limiar anaeróbio/máxima fase estável do lactato ${ }^{11,12}$, até de modo all-out ${ }^{13}$. Vale lembrar que tais exercícios foram incorporados nas diretrizes da Sociedade Europeia de Cardiologia para reabilitação de pacientes com insuficiência cardíaca ${ }^{14}$, por atuar sobre mecanismos centrais ${ }^{15-18}$ e periféricos ${ }^{15}$ que incrementam a aptidão física.

Previamente, observou-se em pessoas com doença arterial coronariana, insuficiência cardíaca e elevado risco cardiovascular que este modelo de exercício pode ser mais tolerado em comparação ao exercício contínuo com intensidade moderada (MICE) ${ }^{9}$. Ele também parece ser mais eficiente para melhorar o pico do consumo de oxigênio $\left(\mathrm{VO}_{2 \text { pico }}\right)$ e função de ejeção do ventrículo esquerdo em pacientes com insuficiência cardíaca crônica, sem riscos adicionais aos programas de reabilitação ${ }^{19}$, e tais melhoras reduz a chance de morbi-mortalidade em diferentes contextos ${ }^{20}$. Evidências apontam para vantagens do HIIT sobre o MICE no que diz respeito à melhoria da aptidão $\mathrm{o}^{21-23}$ e redução na pressão arterial de repouso ${ }^{20}$, distensibilidade arterial, função endotelial, capacidade oxidativa muscular e estoques de glicogênio ${ }^{15}$. Além disso, o aumento do $\mathrm{VO}_{2 \text { pico }}$ poderia reduzir a taxa de mortalidade em aproximadamente $15 \%{ }^{20}$.

Assim, este estudo objetivou quantificar o tamanho do efeito de intervenções com exercícios MICE e HIIT em variáveis cardiovasculares de pacientes com infarto agudo do miocárdio (IAM), doença arterial coronariana (DAC) e insuficiência cardíaca (IC). Adicionalmente foram testadas as respostas para fração de ejeção do ventrículo esquerdo (LVEF) e para vasodilatação mediada pelo fluxo (FMD).

\section{MÉTODOS}

Este estudo de metanálise foi conduzido a partir da análise de ensaios clínicos randomizados. A revisão sistemática de literatura e a realização de seus passos metodológicos seguiram as indicações do modelo PRISMA - Preferred Reporting Items for Systematic reviews and Meta-Analyses ${ }^{24}$.

A busca dos artigos incluiu estudos produzidos nos últimos 10 anos e foi realizada entre os meses de outubro e novembro de 2014. A mesma foi realizada por três pesquisadores (mestres em educação física) de forma independente e, quando não houve consenso entre os revisores sobre a inclusão dos manuscritos no estudo, eles se reuniram e consultaram um quarto pesquisador que avaliou o trabalho e definiu sua inclusão ou não na revisão. 
Para acessar os estudos, foram conduzidas buscas nas bases de dados eletrônicas PubMed, EBSCOhost e Science Direct. Utilizaram-se os termos da base de dados Medical Subject Heading (MeSH), a saber: 'cardiovascular diseases' OR 'metabolic diseases' OR 'chronic diseases'. Em conjunto com os termos MESH, foram utilizados 'bigh intensity training/exercise', OR 'interval training/exercise', $O R$ 'intermittent training/exercise', $O R$ 'low volume training/exercise' $O R$ 'aerobic interval training/exercise'. Além da busca pelos descritores, pesquisaram-se os nomes dos autores que escrevem sobre o tema e foram recuperadas pesquisas encontradas nas referências dos estudos incluídos na revisão.

Inicialmente os artigos foram avaliados pelos títulos, que deveriam informar sobre a comparação entre o exercício intermitente e outros modelos de exercício que fossem realizados de forma contínua apenas em indivíduos com algum tipo de doença cardíaca. Na sequência, pela leitura dos resumos, foram mantidos apenas estudos que apresentaram comparações pré e pós determinado período de intervenção. Por fim, os artigos ainda elegíveis nesta etapa foram lidos na íntegra e se mantiveram apenas os que apresentavam pelo menos resultados do consumo de oxigênio pico $\mathrm{VO}_{2 \text { pico }}$, considerado principal variável de interesse.

Após seleção final dos estudos, os mesmos foram avaliados e classificados a partir da Physiotherapy Evidence Based Database (PEDro) para fins de descrição, com intuito de verificar-se a validade interna dos trabalhos e a existência de informações suficientes para interpretação da estatística apresentada nos mesmos $^{25}$. Esta escala é composta por 11 questões que têm como finalidade permitir tal avaliação e, quanto maior o número de questões estiverem apresentadas nos estudos, melhor seu design e facilidade de interpretação dos mesmos. Após avaliação dos estudos, foram extraídos os principais resultados e tabulados em planilha do Excel 2010. A análise dos dados ocorreu no pacote estatístico BioEstat 5.3. Listaram-se os artigos incluídos assim como todos excluídos com descrição de porque os mesmos não se enquadravam a pesquisa.

Para apresentação dos dados descritivos foram utilizados valores absolutos, mediana, valores mínimos e máximos para algumas variáveis, bem como médias e erros padrão para outras. Para as comparações das investigações utilizou-se o número de indivíduos em cada protocolo de exercício (intermitente x contínuo), a média e o desvio padrão de cada estudo na condição pós intervenção, para isto utilizou-se a ferramenta estatística metanálise para dados contínuos do pacote estatístico selecionado. Os resultados são apresentados através da média das diferenças, erro padrão, escore Z, valor p e intervalo de confiança. Os resultados individuais dos estudos apresentam resultados através da diferença entre as médias, intervalos de confiança superior e inferior e o peso. Estas análises foram feitas para o $\mathrm{VO}_{2 \text { pico }}, \mathrm{FC}_{\text {pico, }} \mathrm{LVEF}$ e FMD.

\section{RESULTADOS}

Foram encontrados 1168 títulos pelos descritores utilizados. Destes, 45 foram selecionados pelo título. Na leitura dos títulos, 18 foram excluídos por terem sido realizados com diabéticos, hipertensos, pacientes com síndrome metabólica, obesos, com doença pulmonar obstrutiva crônica (DPOC) e idosos $(\mathrm{n}=27)$. Na sequência, a partir da leitura dos resumos foram excluídos mais 18 estudos. Destas exclusões, cinco ocorreram porque os estudos não apresenta- 
rem a medida principal $\left(\mathrm{VO}_{\text {2pico }}\right)$, três por terem sido encontrados em duplicata nas bases de dados utilizadas, dois por estarem como desfecho principal a perda da condição do $\mathrm{VO}_{2 \text { pico }}$ em períodos de acompanhamento, dois por terem sido publicados em períodos anteriores ao critério de inclusão, sendo um de 1988 e outro de 1998, um por envolver treinamento em circuito, dois por apresentação de dados através de mediana e semi-amplitude interquartílica, um por ter adicionado treinamento resistido aos protocolos, um por não apresentar grupo de exercício moderado, um por ser apenas o resumo publicado em evento de sociedade internacional e publicado em suplemento de revista da área e um por tratar de comparativo do número de eventos ocorridos pelo número de horas de sessão de exercícios intermitentes ou contínuos em programas de reabilitação. Deste modo, foram mantidos oito estudos para leitura na íntegra. Na leitura, foram identificados mais quatro trabalhos nas referências dos trabalhos, estes foram resgatados e incluídos na análise final, que foi composta por 12 estudos (FIGURA 1). O Quadro 1 apresenta os estudos com suas características, tipo e paciente, característica do treinamento, frequência e duração, bem como principal desfecho.

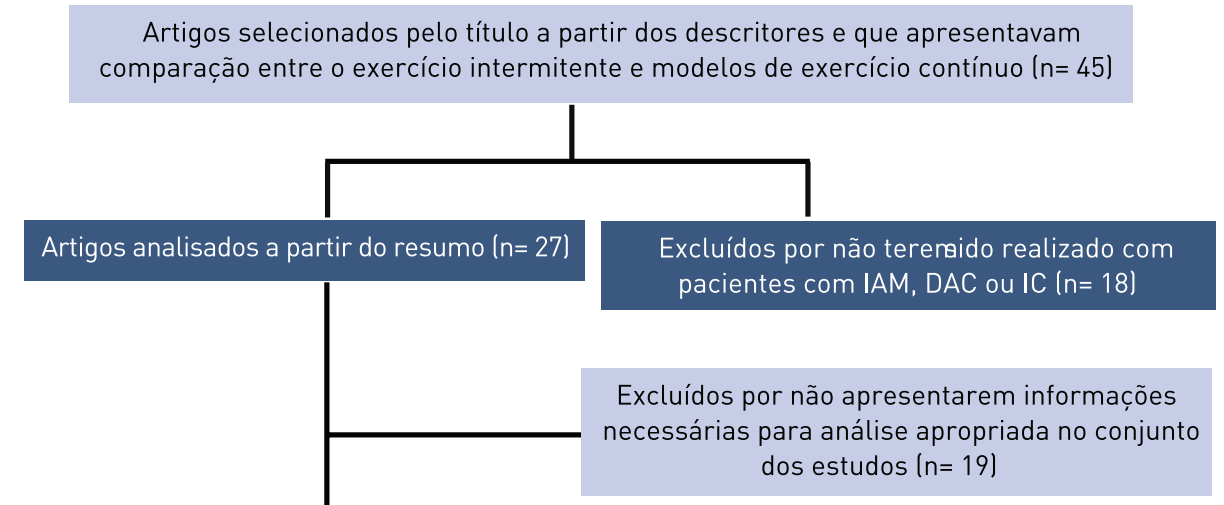

Mantidos para leitura na íntegra $(n=8)$

Incluídos a partir de outras referências $(n=4)$

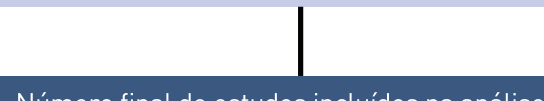

Número final de estudos incluídos na análise $(n=12)$

FIGURA 1 -Fluxograma dos procedimentos para seleção de artigos inseridos na análise final do estudo.

Dos 12 estudos incluídos na análise final, um foi realizado com pacientes pós IAM, três com pacientes com DAC e oito com pacientes com insuficiência cardíaca. Destes estudos, dois apresentaram oito pontos na escala PEDro; sete exibiram sete pontos; um chegou a seis pontos e dois obtiveram cinco pontos. De modo geral $75 \%$ dos estudos apresentaram pontuação igual ou superior a sete $(n=9)$ dos onze possíveis na escala.

A média de tempo das intervenções dos estudos foi de 12,8 semanas; no entanto oito estudos tiveram duração de 12 semanas, um teve duração de oito (8), uma duração de 10 semanas, um atingiu 16 semanas de duração e o que 
QUADRO 1 - Síntese dos estudos incluídos na metanálise.

\begin{tabular}{|c|c|c|c|c|c|c|}
\hline Estudo & $\begin{array}{l}\text { Características } \\
\text { do grupo }\end{array}$ & $\begin{array}{l}\text { Número de } \\
\text { sujeitos }\end{array}$ & Característica do treino & $\begin{array}{l}\text { Frequência } \\
\text { e duração }\end{array}$ & Equipamento & Desfecho \\
\hline $\begin{array}{l}\text { Moholdt et } \\
\text { al. } .^{35}\end{array}$ & $\begin{array}{l}\text { Infarto agudo } \\
\text { do miocárdio }\end{array}$ & $\begin{array}{l}\mathrm{HIIT}=30 \\
\mathrm{MICE}=59\end{array}$ & $\begin{array}{l}\text { HIIT } 4 \text { x de } 4 \text { minutos }(85-95 \% \text { da } \\
\text { FC } \text { I }_{\text {max }} \text { com } 3 \text { minutos de intervalo } \\
\text { a } 70 \% \text { da } \mathrm{FC} \text { max. Tempo total } 38 \\
\text { minutos. } \\
\text { MICE } 60 \text { minutos em casa com } \\
\text { aquecimento e exercícios de } \\
\text { fortalecimento e } 35 \text { minutos de } \\
\text { caminhada. }\end{array}$ & $\begin{array}{l}2 \times \text { semana } \\
\text { durante } 12 \\
\text { semanas }\end{array}$ & $\begin{array}{l}\text { Caminhada } \\
\text { na esteira }\end{array}$ & $\begin{array}{l}\text { O HIIT aumentou mais o pico de } \\
\text { captação de } \mathrm{O}_{2} \text { em comparação } \\
\text { ao MICE em pacientes que } \\
\text { tinham infartado. }\end{array}$ \\
\hline $\begin{array}{l}\text { Conraads et } \\
\text { al. }{ }^{27}\end{array}$ & $\begin{array}{l}\text { Doença } \\
\text { arterial } \\
\text { coronariana }\end{array}$ & $\begin{array}{l}\mathrm{HIIT}=100 \\
\mathrm{MICE}=100\end{array}$ & $\begin{array}{l}\text { HIIT ( } 85-95 \% \mathrm{VO}_{2 \text { pico }} \text { ou } 90-95 \mathrm{FC}_{\text {pico }} \text { ) } \\
10 \text { min aquecimento } 4 \times 4 \text { minutos } \\
\text { de esforço por } 3 \text { de pausa total } 38 \\
\text { minutos. } \\
\text { MICE }\left(60-70 \% \mathrm{VO}_{2 \text { icco }} \text { ou } 65-75 \%\right. \\
\mathrm{FC}_{\text {pico }} \text { ) exercício contínuo, } 5 \text { minutos } \\
\text { de aquecimento, } 37 \text { de exercício e } 5 \\
\text { de recuperação - total } 47 \text { minutos }\end{array}$ & $\begin{array}{l}3 \times \text { semana } \\
\text { durante } 12 \\
\text { semanas }\end{array}$ & $\begin{array}{l}\text { Ciclo } \\
\text { ergômetro }\end{array}$ & $\begin{array}{l}\text { Foi observada melhoria } \\
\text { semelhante na função } \\
\text { endotelial entre o HIIT e o MICE } \\
\text { em pacientes com DAC. }\end{array}$ \\
\hline $\begin{array}{l}\text { Rognmo et } \\
\text { al. } 40\end{array}$ & $\begin{array}{l}\text { Doença } \\
\text { arterial } \\
\text { coronariana }\end{array}$ & $\begin{array}{l}\mathrm{HIIT}=8 \\
\mathrm{MICE}=9\end{array}$ & $\begin{array}{l}\text { HIIT lentre } 85 \text { e } 95 \% \text { da } \mathrm{FC}_{\text {pico }} \text { ) } 5 \\
\text { minutos de aquecimento seguido de } 4 \\
\times 4 \text { minutos entre } 80 \text { - } 90 \% \mathrm{VO}_{2 \text { pico, }} 85 \\
\text { e } 95 \% \mathrm{FC}_{\text {pice }} \text { com intervalos ativos de } \\
3 \text { minutos entre } 50 \text { e } 60 \% \mathrm{VO}_{2 \text { pico, }} 65 \text { - } \\
75 \% \mathrm{FC} \text { pico }- \text { tempo total } 33 \text { minutos. } \\
\text { MICE (entre } 60 \text { e } 70 \% \text { da } \mathrm{FC}_{\text {pico }} \text { ) } \\
\text { tempo total } 41 \text { minutos. }\end{array}$ & $\begin{array}{l}3 \times \text { semana } \\
\text { durante } 10 \\
\text { semanas }\end{array}$ & $\begin{array}{l}\text { Caminhada } \\
\text { na esteira }\end{array}$ & $\begin{array}{l}\text { O HIIT provocou maior aumento } \\
\text { no VO2pico em comparação ao } \\
\text { MICE em pacientes com DAC } \\
\text { estável. }\end{array}$ \\
\hline $\begin{array}{l}\text { Currie et } \\
\text { al. }{ }^{26}\end{array}$ & $\begin{array}{l}\text { Doença } \\
\text { arterial } \\
\text { coronariana }\end{array}$ & $\begin{array}{l}\mathrm{HIIT}=7 \\
\mathrm{MICE}=7\end{array}$ & 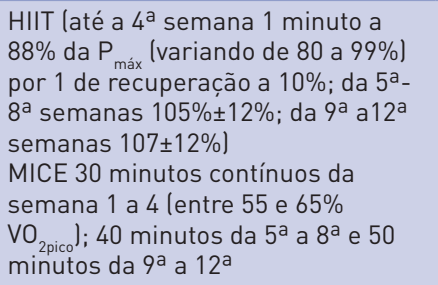 & $\begin{array}{l}2 \times \text { semana } \\
\text { durante } 12 \\
\text { semanas }\end{array}$ & $\begin{array}{l}\text { Ciclo } \\
\text { ergômetro }\end{array}$ & $\begin{array}{l}\text { Nenhum dos modelos de } \\
\text { exercício provocou alterações na } \\
\text { função autonômica cardíaca em } \\
\text { pacientes com DAC. }\end{array}$ \\
\hline $\begin{array}{l}\text { Freyssin et } \\
\text { al.22 }\end{array}$ & $\begin{array}{l}\text { Insuficiência } \\
\text { cardíaca }\end{array}$ & $\begin{array}{l}\mathrm{HIIT}=12 \\
\mathrm{MICE}=14\end{array}$ & $\begin{array}{l}\text { HIIT } 3 \text { séries de } 12 \text { repetições de } \\
30 \text { segundos de esforço entre } 50 \text { e } \\
80 \% \text { da } P_{\text {máx }} \text { por } 60 \text { de recuperação } \\
\text { total com intervalo de } 5 \text { minutos } \\
\text { entre as séries, total } 168 \text { min/sem } \\
\text { de exercício } \\
\text { MICE } 45 \text { minutos contínuos com } \\
\text { FC correspondente ao limiar } \\
\text { ventilatório } 1 \text {, total } 360 \mathrm{~min} / \mathrm{sem}\end{array}$ & $\begin{array}{l}5 \times \text { semana } \\
\text { durante } 8 \\
\text { semanas }\end{array}$ & $\begin{array}{l}\text { Ciclo } \\
\text { ergômetro }\end{array}$ & $\begin{array}{l}\text { O HIIT parece ser mais efetivo } \\
\text { que o MICE na melhoria da } \\
\text { capacidade submáxima de } \\
\text { exercício em pacientes com } \\
\text { insuficiência cardíaca. }\end{array}$ \\
\hline Fu et al. ${ }^{32}$ & $\begin{array}{l}\text { Insuficiência } \\
\text { cardíaca }\end{array}$ & $\begin{array}{l}\text { HIIT }=15 \\
M I C E=15\end{array}$ & $\begin{array}{l}\text { HIIT } 5 \text { vezes de } 3 \text { minutos a } 80 \% \\
(\sim 80 \% \text { FCR }) \text { VO } \\
\text { minutos de intervalo a } 40 \% \mathrm{VO}_{2 \text { pico }} \\
\text { minuaras } 3 \\
\mathrm{MICE} 30 \text { minutos contínuos a } 60 \% \\
\mathrm{VO}_{2 \text { pico }}(\sim 60 \% \text { FCR })\end{array}$ & $\begin{array}{l}3 x \text { semana } \\
\text { durante } 12 \\
\text { semanas }\end{array}$ & $\begin{array}{l}\text { Ciclo } \\
\text { ergômetro }\end{array}$ & $\begin{array}{l}\text { O HIIT pode melhorar as } \\
\text { respostas hemodinâmicas } \\
\text { centrais e periféricos ao } \\
\text { exercício. No entanto, MICE pode } \\
\text { apenas manter as respostas } \\
\text { fisiológicas ao exercício no nível } \\
\text { pré intervenção. }\end{array}$ \\
\hline $\begin{array}{l}\text { lellamo et } \\
\text { al. }^{33}\end{array}$ & $\begin{array}{l}\text { Insuficiência } \\
\text { cardíaca }\end{array}$ & $\begin{array}{l}\mathrm{HIIT}=8 \\
\mathrm{MICE}=8\end{array}$ & $\begin{array}{l}\text { HIIT de } 2 \text { a } 4 \text { séries de } 4 \text { minutos } \\
\text { entre } 75 \text { e } 80 \% \text { da FCR com } \\
\text { intervalos ativos entre as séries } \\
\text { entre } 45 \text { e } 50 \% \text { da FCR } \\
\text { MICE } 30 \text { a } 45 \text { minutos entre } 45 \text { e } \\
60 \% \text { da FCR }\end{array}$ & $2 x$ a $5 x$ & $\begin{array}{l}\text { Caminhada } \\
\text { na esteira }\end{array}$ & $\begin{array}{l}\text { Os dois modelos de exercício } \\
\text { induziram a modificações } \\
\text { significativas na capacidade } \\
\text { aeróbia em pacientes com } \\
\text { insuficiência cardíaca após } \\
\text { infarto. }\end{array}$ \\
\hline $\begin{array}{l}\text { Wisloff et } \\
\text { al. }{ }^{8}\end{array}$ & $\begin{array}{l}\text { Insuficiência } \\
\text { cardíaca }\end{array}$ & $\begin{array}{l}\mathrm{HIIT}=9 \\
\mathrm{MICE}=9\end{array}$ & $\begin{array}{l}\text { HIIT } 4 \text { séries de } 4 \text { minutos entre } 90 \\
\text { e } 95 \% \mathrm{FC}_{\text {pico }} \text { o tempo total da sessão } \\
\text { foi de } 38 \text { minutos } \\
\text { MICE entre } 70 \% \text { e } 75 \% \text { da } \mathrm{FC}_{\text {pico }} \text { com } \\
\text { duração de } 47 \text { minutos }\end{array}$ & $\begin{array}{l}3 \times \text { semana } \\
\text { durante } 12 \\
\text { semanas }\end{array}$ & $\begin{array}{l}\text { Caminhada } \\
\text { na esteira }\end{array}$ & $\begin{array}{l}\text { O VO } \mathrm{V}_{2 \text { pico }} \text { aumentou mais } \\
\text { com O HIIT em comparação } \\
\text { ao MICE }(46 \% \text { versus } 14 \% \text {, } \\
\text { respectivamente - } p<0,001) \text { e } \\
\text { foi significativamente associado } \\
\text { com o remodelamento do } \\
\text { ventrículo esquerdo. Sendo a } \\
\text { intensidade do exercício um } \\
\text { fator importante para melhorar } \\
\text { também a função endotelial e a } \\
\text { qualidade de vida de pacientes } \\
\text { com insuficiência cardíaca. }\end{array}$ \\
\hline
\end{tabular}




\begin{tabular}{|c|c|c|c|c|c|c|}
\hline $\begin{array}{l}\text { Smart et } \\
\text { al. }^{34}\end{array}$ & $\begin{array}{l}\text { Insuficiência } \\
\text { cardíaca }\end{array}$ & $\begin{array}{l}\mathrm{HIIT}=10 \\
\mathrm{MICE}=13\end{array}$ & $\begin{array}{l}\text { HIIT } 60 \text { minutos de exercício a } 70 \% \\
\text { VO }(60 \text { segundos de esforço } \times 60 \\
\text { segundos de pausa) } \\
\text { MICE } 30 \text { minutos contínuos a } 70 \% \\
V_{2 \text { pico }}\end{array}$ & $\begin{array}{l}3 \times \text { semana } \\
\text { por } 16 \\
\text { semanas }\end{array}$ & $\begin{array}{l}\text { Ciclo } \\
\text { ergômetro }\end{array}$ & $\begin{array}{l}\text { O HIIT aumentou mais a } \\
\text { capacidade funcional em } \\
\text { comparação ao MICE. }\end{array}$ \\
\hline $\begin{array}{l}\text { Koufaki et } \\
\text { al. }^{38}\end{array}$ & $\begin{array}{l}\text { Insuficiência } \\
\text { cardíaca }\end{array}$ & $\begin{array}{l}\mathrm{HIIT}=8 \\
\mathrm{MICE}=9\end{array}$ & $\begin{array}{l}\text { HIIT } 30 \text { segundos a } 100 \% \text { do pico de } \\
\text { potência } \times 1 \text { minuto a } 20-30 \% \text { pico } \\
\text { de potência ( } 2 \times 15 \text { minutos). } \\
\text { MICE } 40 \text { minutos contínuos a } 40 \text { - } \\
60 \% \mathrm{VO}_{2 \text { pico. }}\end{array}$ & $\begin{array}{l}3 \times \text { semana } \\
\text { durante } 24 \\
\text { semanas }\end{array}$ & $\begin{array}{l}\text { Ciclo } \\
\text { ergômetro }\end{array}$ & $\begin{array}{l}\text { O HIIT é uma modalidade de } \\
\text { treinamento viável e bem } \\
\text { tolerado em programas de } \\
\text { reabilitação cardíaca, mas seus } \\
\text { efeitos não foram melhores que } \\
\text { o MICE. }\end{array}$ \\
\hline $\begin{array}{l}\text { Dimopoulus } \\
\text { et al. }{ }^{39}\end{array}$ & $\begin{array}{l}\text { Insuficiência } \\
\text { cardíaca }\end{array}$ & $\begin{array}{l}\mathrm{HIIT}=10 \\
\mathrm{MICE}=14\end{array}$ & $\begin{array}{l}\text { HIIT } 30 \text { segundos de exercício a } \\
100 \% \text { do pico da taxa de trabalho } \\
\text { por } 30 \text { segundos de pausa por } 40 \\
\text { minutos. } \\
\text { MICE } 40 \text { minutos de exercício } \\
\text { contínuo a } 50 \% \text { do pico da taxa de } \\
\text { trabalho. } \\
\text { A intensidade foi aumentada a cada } \\
\text { mês em } 5 \% \text { para o MICE e } 10 \% \text { para } \\
\text { o HIIT }\end{array}$ & $\begin{array}{l}3 \text { x semana } \\
\text { durante } 12 \\
\text { semanas }\end{array}$ & $\begin{array}{l}\text { Ciclo } \\
\text { ergômetro }\end{array}$ & $\begin{array}{l}\text { Os dois modelos de exercício } \\
\text { melhoram a capacidade de } \\
\text { se exercitar em pacientes } \\
\text { com insuficiência cardíaca. } \\
\text { Entretanto o HIIT melhora mais } \\
\text { a diferença entre a FC } \\
\text { apico a FC } \\
\text { do exercício, que é um marnuto da interrupção } \\
\text { de atividade parassimpática, } \\
\text { sugerindo maior contribuição } \\
\text { do SNA. }\end{array}$ \\
\hline $\begin{array}{l}\text { Roditis et } \\
\text { al. }^{31}\end{array}$ & $\begin{array}{l}\text { Insuficiência } \\
\text { cardíaca }\end{array}$ & $\begin{array}{l}\mathrm{HIIT}=11 \\
\mathrm{MICE}=10\end{array}$ & $\begin{array}{l}\text { HIIT } 30 \text { segundos de exercício a } \\
100 \% \text { do pico da taxa de trabalho } \\
\text { por } 30 \text { segundos de pausa por } 40 \\
\text { minutos. } \\
\text { MICE } 40 \text { minutos de exercício } \\
\text { contínuo a } 50 \% \text { do pico da taxa de } \\
\text { trabalho. } \\
\text { Durante o } 2^{\circ} \text { e o } 3^{\circ} \text { mês as } \\
\text { intensidades foram } 55 \text { e } 60 \% \text { do } \\
\text { pico de potência de trabalho para o } \\
\text { MICE e } 110 \text { e } 120 \% \text { para o HIIT. }\end{array}$ & $\begin{array}{l}3 \text { x semana } \\
\text { durante } 12 \\
\text { semanas }\end{array}$ & $\begin{array}{l}\text { Ciclo } \\
\text { ergômetro }\end{array}$ & $\begin{array}{l}\text { Os dois modelos de exercício } \\
\text { melhoraram a cinética do } \mathrm{O}_{2} \\
\text { em pacientes com insuficiência } \\
\text { cardíaca. Porém a fase II } \\
\text { da cinética que é um índice } \\
\text { indireto da capacidade oxidativa } \\
\text { do músculo é mais afetada pelo } \\
\text { MICE. }\end{array}$ \\
\hline
\end{tabular}

teve duração mais longa foi de 24 semanas. Sete destes foram realizados com pacientes de ambos os sexos e cinco apenas com homens.

No somatório dos estudos houve 527 participantes. Destes 239 realizaram as sessões de exercício intermitente com uma mediana de 11 participantes. O que teve menos envolveu sete participantes ${ }^{26}$ e o que teve maior número recrutou $100^{27}$. Em relação a participação nos grupos MICE, 276 sujeitos foram alocados para este modelo de exercício com mediana de 13,5 participantes por estudo. As características gerais dos participantes dos estudos estão apresentadas na tabela 1 .

TABELA 1 - Descrição das características gerais dos participantes dos estudos, através de média \pm dp e valores mínimos e máximos.

\begin{tabular}{lcccccccc}
\hline \multirow{2}{*}{ Descrição } & \multicolumn{4}{c}{ Exercício intermitente } & \multicolumn{4}{c}{ Exercício contínuo } \\
\cline { 2 - 9 } & Média & $d p$ & Mínimo & Máximo & Média & $d p$ & Mínimo & Máximo \\
\hline Idade (anos) & 61,88 & 5,89 & 54,00 & 76,50 & 62,43 & 4,85 & 55,00 & 74,40 \\
\hline IMC* (kg/m²) & 27,22 & 1,54 & 24,50 & 28,90 & 27,11 & 1,56 & 24,10 & 29,50 \\
\hline$V_{2}{ }_{2 \text { pico }}(\mathrm{mL} / \mathrm{kg} \cdot \mathrm{min}) \#$ & 19,38 & 7,10 & 10,70 & 31,80 & 19,53 & 7,05 & 10,60 & 32,20 \\
\hline
\end{tabular}

IMC: Índice de Massa Corporal; * Em relação ao IMC obteve-se informações de 9 estudos. \#Valores referentes à linha de base.

Para analisar as diferenças no $\mathrm{VO}_{2 \text { pico }}$ após a intervenção, foram utilizados os 12 estudos revisados e a sumarização destes achados é apresentada na Figura 2. Nela, evidencia-se vantagem do HIIT sobre o MICE, com média das diferenças de 2,8 mL/kg.min ( $\mathrm{p}=0,0001)$. 
No entanto, para a $\mathrm{FC}_{\text {pico }}$, um destes estudos não trazia a informação ${ }^{22} \mathrm{e}$, consequentemente, não foi incluído e a análise para esta variável é apresentada na Figura 3. Para esta variável, não houve diferença entre os protocolos de treinamento $(\mathrm{p}<0,246)$.

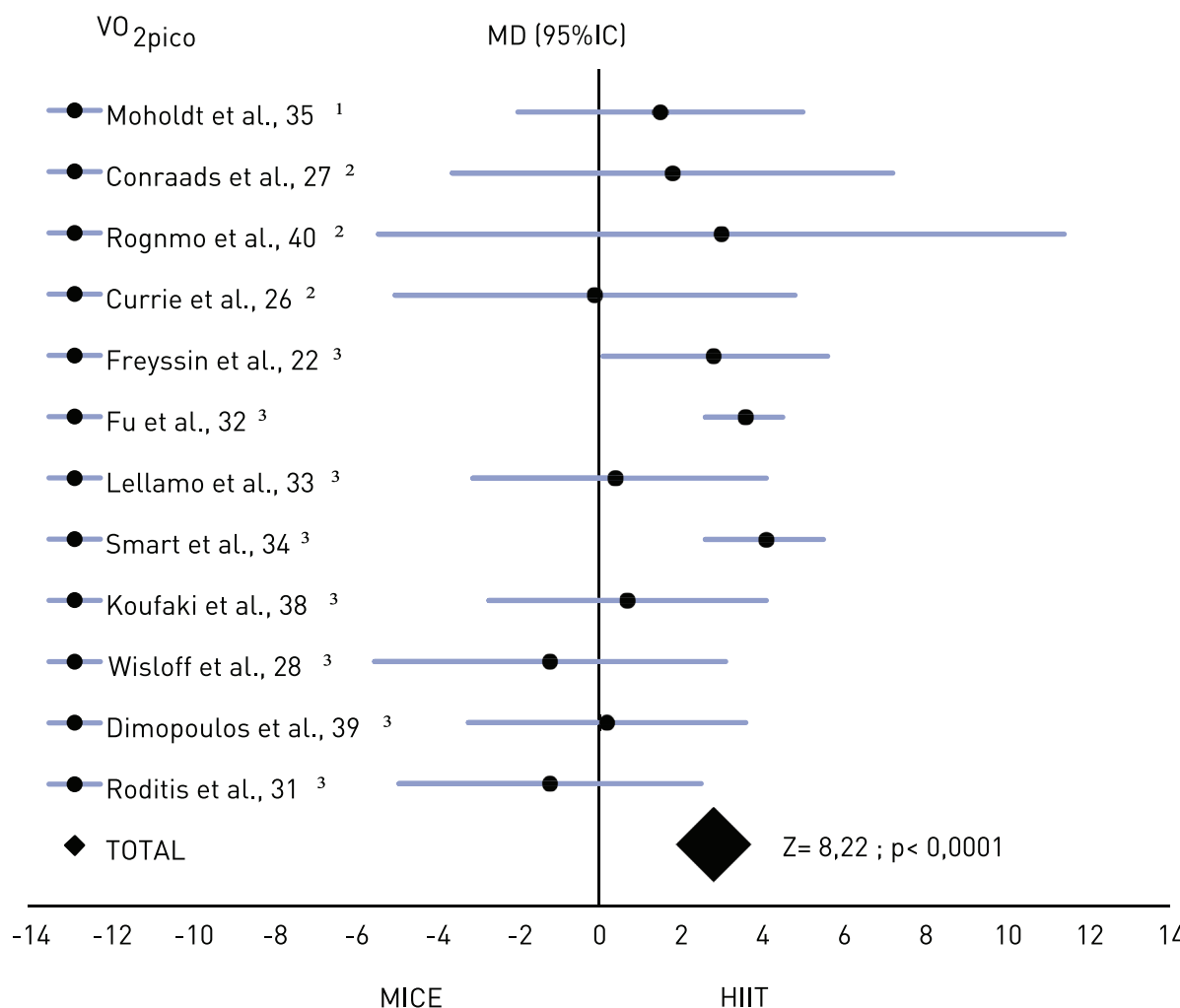

FIGURA 2 - Comparação das respostas da VO ${ }_{2 p i c o}$ entre protocolos HIIT e MICE (n=12).

1: infarto agudo do miocárdio; 2: doença arterial coronariana; 3: insuficiência cardíaca; MD: Média das diferenças; HIIT: Exercício Intermitente de Alta Intensidade; MICE: Exercício contínuo de intensidade moderada.

Ainda na Figura 3 são apresentados os dados da síntese dos estudos que investigaram a LVEF. Dos 12 estudos elegíveis, apenas 4 apresentaram esta medida, sendo que um destes foi excluído por não apresentar os valores de média e desvio padrão ${ }^{28}$. Como síntese, os resultados sugerem que protocolos de HIIT parecem ser mais eficientes para a melhora da LVEF ( $p=0,001)$.

Por fim, a Figura 3 também ilustra a síntese das repostas da FMD a partir dos protocolos de treinamento. A partir destes dados sugere-se que não há diferença entre os protocolos para esta variável $(\mathrm{p}=0,9)$.

\section{DISCUSSÃO}

O principal achado desta metanálise foi identificar que o HIIT apresenta melhora na aptidão cardiorrespiratória maior ( 2 vezes) do que MICE. A sumarização dos ensaios clínicos randomizados indica que, quando considerado o $\mathrm{VO}_{\text {2pico, }}$ protocolos de HIIT parecem apresentar efeito superior na reabilitação de pacientes com problemas cardiovasculares, quando comparados aos MICE $(p=0,001)$. Efeito superior do HIIT também pode ser identificado na melhora no volume de ejeção do ventrículo esquerdo $(\mathrm{p}=0,001)$. Já quanto 
LVEF

- Fu et al., $32^{3}$

- Lellamo et al., $33^{3}$

- Smart et al., $34^{3}$

- total lVeF

FMD

Moholdt et al., 35

Smart et al., $34^{3}$

- Conraads et al., $27^{2}$

- TOTAL FMD

FC pico

-Moholdt et al., 35

- Conraads et al., $27^{2}$

Rognmo et al., $40^{2}$

- Currie et al., $26^{2}$

- Fu et al., $32^{3}$

- Lellamo et al., $33^{3}$

- Smart et al., $34^{3}$

- Koufaki et al., 38

- Wisloff et al., $28^{3}$

-Dimopoulos et al., 39

- Roditis et al., $31^{3}$

- total FCpico
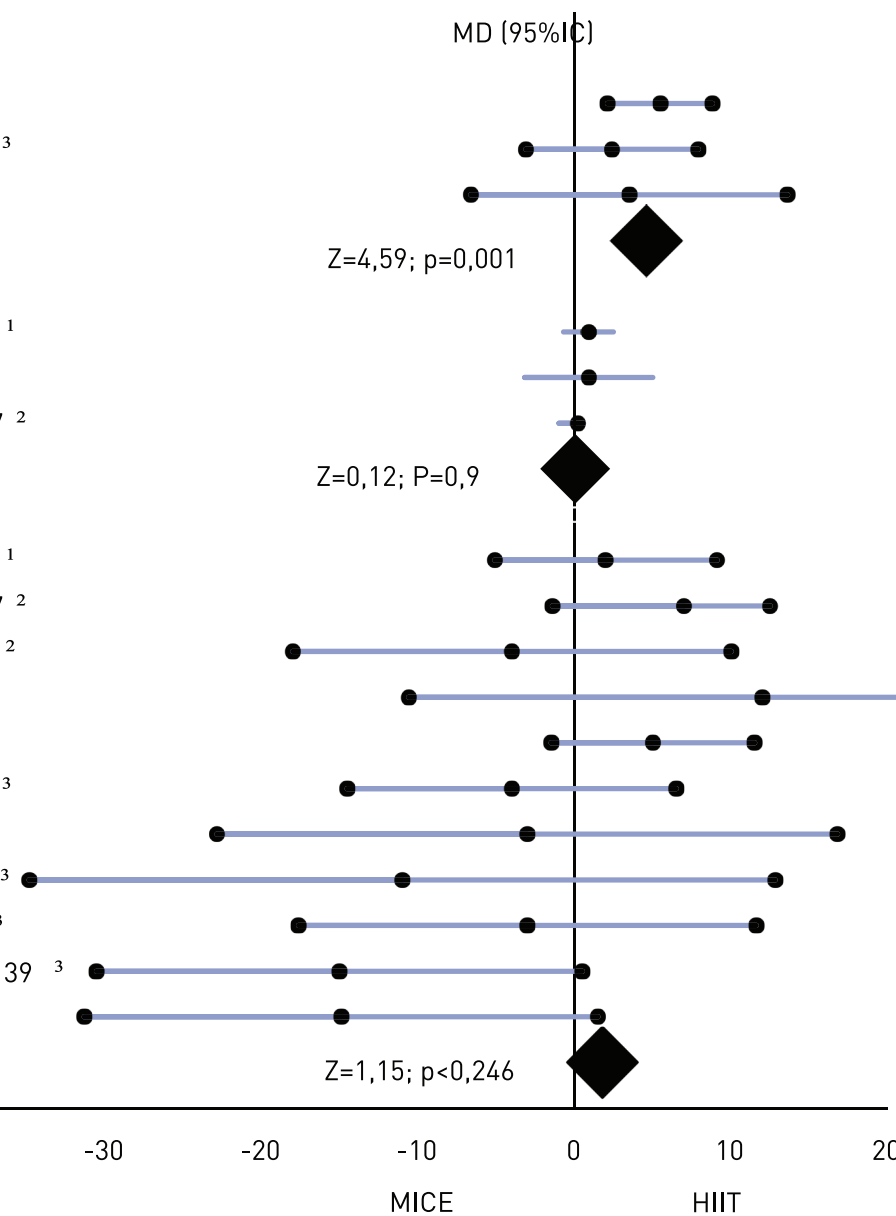
tocolos HIIT e MICE.

1: infarto agudo do miocárdio; 2: doença arterial coronariana; 3: insuficiência cardíaca; MD: Média das diferenças; HIIT: Exercício Intermitente de Alta Intensidade; MICE: Exercício contínuo de intensidade moderada.

$\mathrm{FC}_{\text {pico }}$ e função endotelial, parece não haver diferença significante entre as propostas de treinamento estudadas ( $\mathrm{p}<0,246$ e $\mathrm{p}=0,9$, respectivamente). Os ECRs incluídos envolveram períodos de intervenção entre 8 e 24 semanas em pacientes com IAM $(n=1)$, DAC $(n=3)$ e IC $(n=8)$.

De modo geral, indica-se que a melhora da aptidão cardiovascular em 1-MET (3,5 mL/kg.min; Equivalente metabólico) é fortemente associada a aumentos de sobrevivência em 10 a $25 \%$ em cardiopatas ${ }^{28}$. Especificamente, nesta metanálise, a média de diferença do $\mathrm{VO}_{2 \text { pico }}$ entre HIIT e MICE foi de $2,8 \mathrm{~mL} / \mathrm{kg}$.min a favor dos intervalados $(\mathrm{p}=0,001)$ e, apesar de os dois protocolos apresentarem melhoras após as intervenções (HIIT $=\sim 17 \%$ vs MICE $=\sim 10 \%$ ), de modo absoluto os protocolos HIIT atingiram relevância clínica para redução da mortalidade $(3,6 \mathrm{~mL} / \mathrm{kg}$.min), o que não ocorreu com protocolos contínuos (2,1 mL/kg.min). Estes dados reforçam as indicações para pacientes com IC de organizações como a Heart Failure Association e a European Association for Cardiovascular Prevention and Rebabilitation que associam treinamentos intervalados de baixa e alta intensidade aos protocolos contínuos e ao treinamento de força ${ }^{14}$. Nestes guias, a sugestão de aplicação de HIIT já é contemplada em pacientes que apresentam $\mathrm{VO}_{2 \text { ico }}$ maior que $18 \mathrm{~mL} / \mathrm{kg} . \mathrm{min}$, tanto para adultos quanto para idosos, ativos ou sedentários ${ }^{14}$. 
Os mecanismos que explicam o aprimoramento do $\mathrm{VO}_{\text {2pico }}$ a partir do HIIT envolvem aspectos prioritariamente periféricos, como o aumento na PGC1- $\alpha$, enzima responsável pela biogênese mitocondrial e na taxa de receptação de $\mathrm{Ca}^{2+}$ pelo retículo sarcoplasmático ${ }^{29,30}$, o que promove maior eficiência da diástole e, consequentemente, maior força e rapidez contrátil na sístole ${ }^{27}$. Adicionalmente, melhoras gerais do sistema cardiovascular também envolvem aspectos centrais, como $\mathrm{LVEF}^{31-33}$, e periféricos, como a FMD ${ }^{26,33,34}$.

Fundamentalmente, até a década de 1980, a aplicação de exercícios em pacientes com redução da LVEF era associada a aumento do risco para morbidades e mortalidade ${ }^{35}$. Apesar disso, atualmente a aplicação de exercícios é bem aceita, inclusive, os estudos incluídos nesta revisão envolvem pacientes com LVEF menor do que 40\%, o que indica presença de doença cardíaca ocasionada por disfunção ventricular. Destes, três avaliaram o impacto do HIIT e do MICE nesta variável ${ }^{31-33}$ e, quando sumarizados, indicaram melhora superior com protocolos intervalados $(\mathrm{p}=0,001)$. Os achados indicaram que além de promover remodelamento cardíaco positivo, pelo aumento do ventrículo esquerdo e consequente aumento do volume de ejeção, o HIIT influenciou na reabilitação do remodelamento patológico ${ }^{31-33}$. Já quanto à $\mathrm{FMD}$, valor menor do que $5,5 \%$ é indicador de aumento da morbidade e mortalidade por eventos cardiovasculares em até três vezes quando comparado a valor maior do que este ${ }^{26,33,34}$. A partir disto, Conraads et al. ${ }^{27}$, indicaram melhora clinicamente significante pela evolução dos pacientes a 6,4\%. Neste caso, apesar de exercícios promoverem aprimoramento e do baixo número de evidências, os resultados desta metanálise não indicam diferença entre HIIT e MICE, o que contraria a hipótese inicial, justificada pelo fato de que um dos mecanismos envolvem o aumento da produção de óxido nítrico, o que teria maior impacto com protocolos de maior intensidade ${ }^{34}$.

Quanto à prescrição do HIIT, algumas indicações foram previamente estabelecidas ${ }^{9,14,29,36}$. Dentre as sugestões, Weston et al. ${ }^{29}$, recomendam que pacientes cardiometabólicos sejam inseridos em programas de HIIT três vezes por semana com duração de 40 min que envolvem esforços de 4 min (85 a $95 \%$ da $\left.\mathrm{FC}_{\text {pico }}\right)$ e recuperação de 3 min (0 a $70 \%$ da $\left.\mathrm{FC}_{\text {pico }}\right)$. Ainda, considerando pacientes com síndrome metabólica (inclusive cardiopatias), Del Vecchio et al. ${ }^{36}$, indicam processo de progressão de HIIT que inicia com protocolos com estímulos mais longos e submáximos e avança para protocolos curtos e máximos até atingir protocolos supramáximos, inclusive com esforços repetidos na maior intensidade possível (all-out). Piepoli et al. ${ }^{14}$, apontam que, em pacientes com IC, alternem-se esforços curtos (10-30seg) de intensidade moderada a alta (50-100\% do pico de capacidade para se exercitar) com recuperações longas $(60-80 \mathrm{seg})$ em intensidade baixa ou de modo passivo. Por fim, quando considerados pacientes com doença coronariana, Guiraud et al. ${ }^{9}$, investigaram quatro diferentes protocolos de HIIT com vistas a identificar um destes como ótimo, considerando tempo até a exaustão, tempo gasto próximo ao $\mathrm{VO}_{2 \max }$, conforto do paciente e segurança. Os protocolos diferiam entre si quanto ao tempo de esforço (15 ou $60 \mathrm{seg})$ e quanto ao tipo de recuperação (passiva ou ativa), todos em razão de esforço e pausa de 1:1. Os autores concluíram que exercícios a $100 \%$ da potência aeróbia máxima eram tolerados e seguros para esta população e que a recuperação passiva promoveu maior tempo até a exaustão e, com isso, o protocolo de $15 \mathrm{seg}$ de esforço e pausa com 
recuperação passiva pareceu ser o mais indicado para equilibrar os parâmetros avaliados (tempo até a exaustão, tempo gasto próximo ao $\mathrm{VO}_{2 \max }$, conforto do paciente e segurança).

Em pacientes com insuficiência cardíaca crônica, constataram-se melhoras no $\mathrm{VO}_{2 \text { pico }}(27 \%)$, duração do exercício (47\%) e captação de O2 durante exercício máximo (18\%), não observadas no protocolo contínuo ${ }^{22}$. Em suma, parece que exercícios intermitentes de alta intensidade se apresentam como estratégia eficiente e segura para pacientes com problemas cardiovasculares. Quando comparados aos tradicionais contínuos usualmente recomendados, eles parecem apresentar maior eficiência $\left(\mathrm{VO}_{2 \text { pico }}\right.$ e LVEF) ou pelo menos eficiência equivalente ( $\mathrm{FC}_{\text {pico }}$ e FMD). Complementarmente, deve-se fazer a ressalva que um dos maiores problemas associados a intervenções com exercícios para reabilitação cardíaca é a aderência aos programas ${ }^{14}$ e se indica que existe boa aderência dos pacientes a esta modalidade de exercício ${ }^{29,35,37}$, que por vezes pode até mesmo ser maior que a aderência a protocolos contínuos ${ }^{34}$.

\section{CONCLUSÃO}

A presente metanálise identificou que exercícios intermitentes de alta intensidade apresentam benefícios superiores ao exercício contínuo executado em intensidades moderadas no que diz respeito a ganhos no pico de consumo máximo de oxigênio e melhoria da capacidade de ejeção do ventrículo esquerdo em pessoas com problemas cardiovasculares. Já a frequência cardíaca e a função endotelial destes pacientes parecem não responder de modo diferente a estes protocolos. Cabe por fim ressaltar que os autores não sugerem a exclusão de outras modalidades de treinamento como protocolos contínuos ou de exercícios de resistência. Deste modo, se destaca a sugestão de que protocolos intermitentes de alta intensidade sejam indicados nas recomendações das diferentes organizações de saúde.

\section{REFERÊNCIAS}

1. World Health Organization [Internet]. The top 10 causes of death. [Atualizado em Maio 2014] Disponível em: http://www.who.int/mediacentre/factsheets/fs310/en/2014.

2. Schmidt MI, Duncan BB, Silva GAe, Menezes AM, Monteiro CA, Sandhi MB, et al. Doenças crônicas não transmissíveis no Brasil: carga e desafios atuais. Lancet. 2011;377(9781):1949-61.

3. Lee I-M, Shiroma EJ, Lobelo F, Puska P, Blair SN, Katzmarzyk PT. Effect of physical inactivity on major non-communicable diseases worldwide: an analysis of burden of disease and life expectancy. Lancet. 2013;380.

4. Ghorayeb N, Costa RVC, Castro I, Daher DJ, Filho JAO, Oliveira MAB. Diretriz em Cardiologia do Esporte e do Exercício da Sociedade Brasileira de Cardiologia e da Sociedade Brasileira de Medicina do Esporte. Arq Bras Cardiol. 2013;100(1 Supl.2): $1-41$.

5. American College of Sports Medicine Position Stand: Exercise for patients with coronary artery disease. Med Sci Sports Exerc. 1994;26(3):i-v.

6. America HFSo, Lindenfeld J, Albert NM, Boehmer JP, Collins SP, Ezekowitz JA, et al. HFSA 2010 Comprehensive Heart Failure Practice Guideline. J Card Fail. 2010;16(6).

7. Eckel RH, Jakicic JM, Ard JD, Jesus JMd, Miller NH, Hubbard VS, et al. AHA/ACC Guideline on Lifestyle Management to Reduce Cardiovascular Risk: A Report of the American College of Cardiology/American Heart Association Task Force on Practice Guidelines. J Am Coll Cardiol. 2013;2014(63):2960-84. 
8. Babraj J, Vollaard N, Keast C. Extremely short duration high intensity interval training substantially improves insulin action in young healthy males. BMC Endocr Disor. 2009;3.

9. Guiraud T, Nigam A, Gremeaux V, Meyer P, Juneau M, Bosquet L. High-intensity interval training in cardiac rehabilitation. Sports Med. 2012;42(7):587-605.

10. Mandroukas A, Heller J, Metaxas T. Cardiorespiratory and metabolic alterations during exercise and passive recovery after three modes of exercise. J Strength Cond Res. 2011;6:1664-72.

11. Laursen PP, Jenkins DG. The scientific basis for high-intensity interval training: optimising training programmes and maximising performance in highly trained endurance athletes. Sports Med. 2002;32(1):53-73.

12. Gaitanos GC, Williams C, Boobis LH, Rooks S. Human muscle metabolismo during intermitente maximal exercise. J Appl Physiol. 1993;75(2):712-9.

13. Gibala MJ, McGee SL. Metabolic adaptations to short-term high-intensity interval training: a little pain for a lot of gain? Exerc Sport Sci Rev. 2008;36(2):58-63.

14. Piepoli MF, Conraads V, Corrà U, Dickstein K, Francis DP, Jaarsma T, et al. Exercise training in heart failure: from theory to practice. A consensus document of the Heart Failure Association and the European Association for Cardiovascular Prevention and Rehabilitation. Eur J Heart Fail. 2011;13:347-57.

15. Buchheit M, Abbiss C, Peiffer J, Laursen P. Performance and physiological responses during a sprint interval training session: relationships with muscle oxygenation and pulmonary oxygen uptake kinetics. J Appl Physiol. 2012;112:767-79.

16. Christmass M, Dawson B, Arthur P. Effect of work and recovery duration on skeletal muscle oxygenation and fuel use during sustained intermittent exercise. J Appl Physiol. 1999;8:436-47.

17. Spencer M, Bishop D, Dawson B, Goodman C. Physiological and metabolic responses of repeated-sprint activities. Sports Med. 2005;12(1025-1044).

18. Trump M, Heigenhauser G, Putnam C, Spriet L. Importance of muscle phosphocreatine during intermittent maximal cycling 1996;5:1574-1580.J Appl Physiol. 1996;5:1574-80.

19. Meyer P, Gayda M, Juneau M, Nigam A. High-Intensity Aerobic Interval Exercise in Chronic Heart Failure. Curr Heart Fail Rep. 2013;10(2):130-8.

20. Keteyian SJ, Brawner CA, al PDSe. Peak aerobic capacity predicts prognosis in patients with coronary heart disease. Am Heart J 2008;156:292-300.

21. Yoshioka M, DoucetE, Pierre S. Impact of high-intensity exercise on energy expenditure, lipid oxidation and body fatness. Int J Obes Relat Metab Disord. 2001;3:332-9.

22. Freyssin C, Verkindt C, Prieur F, Benaich P, Maunier S, Blanc P. Cardiac Rehabilitation in Chronic Heart Failure: Effect of an 8-Week, High-Intensity Interval Training Versus Continuous Training. Arch Phys Med Rehabil. 2012;93.

23. Gutin B BP, Owens S. 2002;7:818-826. Effects of exercise intensity on cardiovascular fitness, total body composition, and visceral adiposity of obese adolescents. J Clin Nutrition. 2002;7:818-26.

24. Liberati A, Altman DG, Tetzlaff J, Mulrow C, Gøtzsche PC, Ioannidis JP, et al. The PRISMA statement for reporting systematic reviews and meta-analyses of studies that evaluate healthcare interventions: explanation and elaboration. BMJ 2009;339:b2700. 2009;339(b).

25. Herbert R, Moseley A, Sherrington C. PEDro: a database of randomised controlled trials in physiotherapy. Health Inf Manag. 1999;28(4):186-8.

26. Currie KD, Rosen LM, Millar PJ, McKelvie RS, MacDonald MJ. Heart rate recovery and heart rate variability are unchanged in patients with coronary artery disease following 12 weeks of highintensity interval and moderate-intensity endurance exercise training. Appl Physiol Nutr Metab. 2013;38:644-50.

27. Conraads VM, Pattyn N, Maeyer CD, Beckers PJ, Coeckelberghs E, Cornelissen VA, et al. Aerobic interval training and continuous training equally improve aerobic exercise capacity in patients with coronary artery disease: The SAINTEXCAD study. Int J Cardiol. 2014; 179:203-10.

28. Wisloff U, Stoylen A, Loennechen JP, Bruvold M, Rognmo O, Haram PM, et al. Superior cardiovascular effect of aerobic interval training versus moderate continuous training in heart failure patients: A randomized study. Circulation. 2007;115:3086-94. 
29. Kaminsky LA, Arena R, Beckie TM, Brubaker PH, Church TS, Forman DE, et al. The importance of cardiorespiratory fitness in the United States: the need for a national registry: a policy statement from the American Heart Association. Circulation. 2013;127:652-62.

30. Weston KS, Wisloff U, Coombes JS. High-intensity interval training in patients with lifestyle-induced cardiometabolic disease: a systematic review and meta-analysis. $\mathrm{Br} \mathrm{J}$ Sports Med. 2014;48:1227-34.

31. Roditis P, Dimopoulos S, Sakellariou D, et al. The effects of exercise training on the kinetics of oxygen uptake in patients with chronic heart failure. Eur J Cardiovas Prev Rehab. 2007; 14: 304-311.

32. Fu T-c, Wang C-H, Lin P-S, Hsu C-C, Cherng W-J, Huang S-C, et al. Aerobic interval training improves oxygen uptake efficiency by enhancing cerebral and muscular hemodynamics in patients with heart failure. Int J Cardiol. 2013;167:41-50.

33. Iellamo F, Manzi V, Caminiti G, Vitale C, Castagna C, Massaro M, et al. Matched dose interval and continuous exercise training induce similar cardiorespiratory and metabolic adaptations in patients with heart failure. Int J Cardiol. 2013;167:2561-5.

34. Smart NA, Steele M. A comparison of 16 weeks of continuous vs intermittent exercise training in chronic heart failure patientes. Congest Heart Fail. 2012;18(4):205-11.

35. Moholdt T, Aamot IL, Granøien I, Gjerde L, Myklebust G, Walderhaug L, et al. Aerobic interval training increases peak oxygen uptake more than usual care exercise training in myocardial infarction patients: a randomized controlled study. Clin Rehabil. 2012;26(33).

36. Meyer P, Gayda M, Juneau M, Nigam A. High-Intensity Aerobic Interval Exercise in Chronic Heart Failure. Curr Heart Fail Rep. 2013;10(2):130-8.

37. Del Vecchio FB, Galliano LM, Coswig VS. Aplicações do exercício intermitente de alta intensidade na síndrome metabólica. Rev Bras Ativ Fis e Saúde. 2013;18(6):669-87.

38. Koufaki P, Mercer TH, George KP, Nolan J Low-volume high-intensity interval training vs continuous aerobic cycling in patients with chronic heart failure: A pragmatic randomised clinical trial of feasibility and effectiveness. J Rehabil Med. 2014; 46(4):348-56

39. Dimopoulos S, Anastasiou-Nana M, Sakellariou D, et al. Effects of exercise rehabilitation program on heart rate recovery in patients with chronic heart failure. Eur J Cardiovasc Prev Rehabil. 2006; 13(1):67-73.

40. Rognmo Ø, Hetland E, Helgerud J, Hoff J, Slørdahl SA. High intensity aerobic interval exercise is superior to moderate intensity exercise for increasing aerobic capacity in patients with coronary artery disease. Eur J Cardiovasc Prev Rehabil. 2004;11(3):216-22.

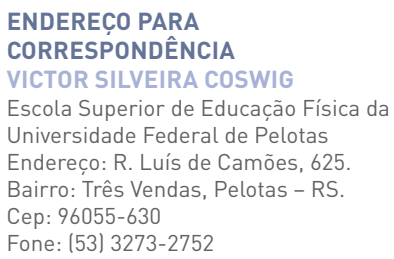

